科 学 通 报

\title{
中国超高压变质岩研究评述 *
}

\author{
从柏林王清晨
}

(中国科学院地质研究所岩石圈构造演化开放研究实验室, 北京 100029)

国际上, 超高压变质岩的研究热始于 1984 年, 以 Chopin 和 Smith 对西阿尔卑斯山变沉积 岩和挪威加里东造山带地壳成因榴辉岩中柯石英的研究 ${ }^{[1,2]}$ 为标志.

在国内, 虽然 60 年代就开始了对苏北榴辉岩的初步研究, 但真正作为超高压变质岩研究 则始于 80 年代后期. 自从许志琴在 1987 年北京怀柔构造会议上口头报道了大别山造山带发 现柯石英 ${ }^{[3]}$ 后, 该带引起了国际注目。潘国强等、周高志等, 董申保等先后与美国刘忠 光 (Liou, J. G.) 等合作, 徐树桐等与土耳其 Sengor 和 Okay 等合作 ${ }^{[4-9}$, 在大别山榴辉岩 中发现了柯石英 (包括假象) 和金刚石, 后者还发现了微量金. 王小民 (1989) 和潘国样 (1990) 先后在大别山发现了柯石英及其假象, 杨建军和法国 D. C. Smith(1989) 在苏鲁榴辉岩 中发现了柯石英和透长石, 并提出了 “苏鲁柯石英榴辉岩省” 的存在. 从柏林等和 Banno 等合 作在该区若干地段的榴辉岩中进一步发现了柯石英、富铝椬石和碱性角闪石 ${ }^{[7,8]}$. 王小燕等 (1993) 和张儒瑗等 (1993) 在河南商麻断裂以西的榴辉岩中也发现了柯石英. 张树业等独立地 对鄂皖蓝片岩带进行了研究. 在短短的几年内, 我国大别山一苏 (北)一鲁 (胶东) 地区就 成为世界著名的超高压变质岩带 (图 1). 进人 90 年代后, 国家自然科学基金委员会不失时机地把



图 1 大别山一苏(北)一鲁 (胶东) 地区超高压变质岩出露范围

199406-28收稿, 1994-07-29 收修改稿.

*国家自然科学基金资助项目. 
这一研究列为 “八五” 期间重点资助项目. 国际岩石圈计划委员会于 1993 年把由中国科学家积 极倡导的 “碰撞造山带的超高压变质作用和地球动力学”研究列为该计划的第 III-6 任务组. 国 际榴辉岩委员会决定于 1995 年在大别山召开 “第三次国际榴辉岩野外学术讨论会”. 这些既是 对近几年我国超高压变质岩研究成果的肯定, 又将促进该研究领域的进一步发展.

\section{1 超高压变质岩的分布与产状}

我国的超高压变质岩研究是从大别山造山带的榴辉岩人手的. 到目前为止, 已经在山东 威海、荣成、诸城、日照、营南, 江苏东海, 安徽潜山、岳西、太湖的榴辉岩中发现了柯石英及其 假象, 并在大别山榴辉岩中发现了金刚石微粒包体 ${ }^{[6}$. 鉴于在河南新县发现了柯石英榴辉 岩 ${ }^{9.109}$, 大别山一苏 (北)一鲁 (胶东) 超高压变质岩带的向西延伸问题已引起人们兴趣. 刘 良、胡能高等最近分别在国内学术会议上口头报道秦岭商南丹凤地区发现了榴辉岩, 虽然他 们出示的矿物分析数据尚不足以为证, 但那里无疑值得进一步工作. 至于我国其它构造带中是 否会有超高压变质岩出露, 也有待于进一步工作.

国外关于榴辉岩与其围岩的关系一直存在着 “就地变质 (in situ)” 和 “外来岩块 (foreign)” 的争论, 随着国际合作的开展, 这一争论也被带人大别山一苏 (北)一鲁 (胶东) 超高压变质 岩带, 但迄今争论的双方都缺乏令人信服的证据. Okay 等 ${ }^{[i]}$ 认为, 大别山超高压变质岩带是一 完整的地体, Wang 等 ${ }^{[12,13]}$ 则认为南大别山是一超高压变质地体, 他们都认为榴辉岩及其围岩共 同经历过超高压变质作用. 徐树桐等 ${ }^{[14}$ 和刘若新等 ${ }^{[15]}$ 坚持外来岩块说. 徐树桐等 ${ }^{[14]}$ 提出的蛇 绿混杂岩尚缺乏必要的岩石学和地球化学证据. 刘若新等 ${ }^{[19}$ 提出的构造混杂岩则缺乏详细的野 外填图资料. Wang 等 ${ }^{[12]}$ 在大别山石马和五庙地区进行了粗略的野外填图, 但这篇文章没有 提供有关围岩片麻岩经受过超高压变质的证据. 后 Wang 等 ${ }^{[13]}$ 补充报道在围岩片麻岩和大理 岩的石榴子石中发现了柯石英假像, 但 “假像”的可信性颇受科学家们的质疑. Okay 等 ${ }^{[1]}$ 发表的 大别山超高压变质岩构造图中标绘了大量面理、线理产状, 但对超高压变质岩的出露范围和边界 的圈定有些草率. 他们把大别山超高压变质岩视作为完整的地体并大胆地解释为无根的飞来 峰, 这种认识缺乏必要的地质和地球物理资料. 董树文等 ${ }^{110}$. 发表的大地电磁测深资料表明, 大别山超高压变质岩带在岳西附近向北倾伏, 埋覆于北大别山地块之下. 王清晨等 ${ }^{[1]}$ 对岳西 一带的超高压变质岩带顶部界线进行了构造地质学研究, 提出该界线为一上盘向北运动的韧 性剪切带, 位于上盘的英云闪长质片麻岩并未经历过超高压变质作用. 从柏林等 ${ }^{\left[{ }^{[18}\right]}$ 最近在大别 山双河地区的地质填图和详细的岩石学研究表明, 榴辉岩的围岩片麻岩按其变质作用特征和 演化历史可分为两类, 一类片麻岩曾与榴辉岩共同经历过超高压变质作用, 它们现在仍共同 产出, 组成超高压岩片; 另一类片麻岩则从未经历过超高压变质作用; 超高压岩片与后一类岩石 呈构造接触. 遗㙳的是, 该研究的填图区域甚小, 松造分析资料仍不充分. 看来, 这一争论的 最后解决将依赖于详细的大比例尺野外地质填图, 精确的同位素定年和精细的岩石变质 $P-T$ 轨迹研究.

\section{2 超高压变质岩的岩石学与矿物学研究}

迄今为止, 超高压变质岩的研究主要集中在矿物学研究方面, 而在发现和识别超高压矿 物及组合方面的竞争也最为激烈. 激烈的竞争带来了这一领域中研究工作的蓬勃发展. 
尽管对超高压变质作用的研究是从榴辉岩人手的, 但并非所有的榴辉岩都经历过超高压 变质作用. Wang 等 ${ }^{[19}$ 的研究表明, 安徽潜山县五庙一带榴辉岩的峰期变质条件为 $744-780^{\circ} \mathrm{C}$, 29-41 kb, 而太湖县黄镇附近只有 $580-610^{\circ} \mathrm{C}, 21-25 \mathrm{~kb}$. 他们指出, 大别山南端榴辉岩 的峰期变质 $P-T$ 条件要低于大别山中部者. Okay ${ }^{[20)}$ 则据此把大别山南部分为 “热、冷” 两个榴 辉岩地体. 这种划分是否恰当尚有待于进一步调查, 主要取决于自北向南的峰期 变质 $P-T$ 条件 是渐变的还是突变的. 详细的 $P-T$ 轨迹研究表明, 无论是否含有柯石英, 大别山一苏 (北) 鲁 (胶南) 的榴辉岩均具有顺时针演化的 P-T 轨迹. 值得提及的是, 张儒瑗等报道了苏鲁地 区石榴子石中发育一种新的不含钠长石而含钠云母的角闪石相矿物组合包体, 他们认为这种 组合的形成压力要高于通常的角闪岩相. 王清晨等 ${ }^{[2]}$ 的研究表明, 山东威海柯石英榴辉岩在 峰期变质后又受到麻粒岩相变质作用的叠加, 经历了增温降压的变质历史.

大别山一苏(北)一鲁 (胶东) 地区的超高压变质作用并非仅影响到榴辉岩. 翟明国等报 道了安徽潜山县韩长冲出露的高压硬玉石英岩, Wang 和 Liou 等对超高压变质的片麻岩和大 理岩分别作了研究. 这些研究表明, 超高压变质岩的原岩种类繁多. 刘雅琴等 ${ }^{[2]}$ 报道了 “类白 片岩”, 但其矿物组合为蓝晶石 + 蓝刚石, 蓝晶石 + 钠云母 + 白云母和蓝晶石 + 黄玉 + 石 英, 但其中无滑石出现, 并非白片岩, 而冠以 “类”字更有失严谨. 白片岩组合是指滑石 + 蓝晶 石, 而且, 即使是白片岩, 它也有高压型和低压型之分, 只有当白片岩组合中出现多硅白云母 时才指示高压 - 低温变质作用. 认为 “类白片岩” 代表高压变质泥质岩尚缺乏实验岩石学资料 的支持.

与榴辉岩共生的超镁铁质岩的超高压变质作用是一个值得研究的问题. 叶凯和徐平以及 焚褀诚等 ${ }^{[23}$ 计算的苏 (北)一鲁 (胶南) 的石榴橄榄岩的平衡温度与压力为 $700-1000{ }^{\circ} \mathrm{C}$, $30-50 \mathrm{~kb}$, 他们把这种较低的古地温梯度 $\left(8-10^{\circ} \mathrm{C} / \mathrm{km}\right)$ 归因于俯冲时的高压变质作用. 遗 惑的是, 他们并没有进行详细的 P-T 轨迹的研究. 张儒瑗等 ${ }^{24}$ 在对苏鲁地区超镁铁质岩的岩 相学研究基础上归纳了 P-T 演化轨迹, 但由于其资料来自几个不同的地点, 因此关于前高压变 质期的资料稍嫌欠缺.杨建军等对江苏东海县芝麻坊石榴橄榄岩的研究 ${ }^{[29}$ 获得了更早阶段的 $P-T$ 轨迹, 表明这些石榴檄榄岩在受到超高压变质前经历了降温减压的演化轨迹. Okay ${ }^{[26}$ 对 大别山南部毛屋石榴檄榄岩的研究则表明, 该岩体是浅部堆晶岩经历了等温增压轨迹而遭受 超高压变质的. 看来, 超镁铁质岩的超高压变质 $P-T$ 轨迹具有因地而异的多样性.

超高压变质作用可引起主要造岩矿物在成分和结构两方面的转变. 这方面的研究有望在 90 年代获得突破性进展. 有迹象表明, 苏 (北)一鲁 (胶东) 超高压变质带的石榴子石中曾发生 过 ${ }^{[8]} \mathrm{Na}^{[8]}(\mathrm{Y}+\mathrm{Yb}) \cdot 2(\mathrm{Ca}, \mathrm{Mn})_{-1}$ 高压置换 (M. Enami, 1994 个人通讯). 由超高压变质作用所 引起的绿辉石的纳米 $(\mathrm{NM} \mu)$ 级晶畴结构变化正在研究之中.

\section{3 超高压变质岩的同位素年代学}

大别山一苏(北)一 鲁 (胶东) 超高压变质岩的变质年代是一个争论已久的问题, 近几年 对榴辉岩测定的各种同位素年龄数据仍跨越晚前寒武纪、古生代、中生代和新生代. 如何评 价和解释这些年龄数据已成为讨论焦点之一. 目前对造成年龄多样性的原因至少有如下 3 种 解释: (1) 原岩的继承年龄; (2)存在着多阶段超高压变质事件; (3) 分析方法选用不当, 没有 注意到过剩氯的存在以及矿物的环带构造引起的不均一性等问题. 
应该指出, 越来越来多的科学家们倾向于认为大别山一苏 (北)一鲁 (胶东) 的超高压变 质作用发生在中生代. 李曙光等 ${ }^{22 n}$ 对同一样品用不同的定年方法进行了测定, 发现 Sm-Nd 法 和 Rb-Sr 法的榴辉岩矿物等时线年龄 (Rb-Sr法：220-224Ma,Sm-Nd 法：226-228Ma) 与地质 资料非常一致, 而多硅白云母的 ${ }^{40} \mathrm{Ar} /{ }^{39} \mathrm{Ar}$ 坪年龄偏老 $(878-943 \mathrm{Ma})$, 推测是因 ${ }^{40} \mathrm{Ar}$ 的过剩所 造成. 他们据此指出, 对超高压变质岩而言, 多硅白云母的 ${ }^{40} \mathrm{Ar} /{ }^{39} \mathrm{Ar}$ 定年结果要慎重使用. Ames 等 ${ }^{[2 x]}$ 认为 U-Pb 体系的封闭温度较高, 有望给出接近超高压变质峰期的精确时间. 但他们发 表的大别山南部榴辉岩的 U-Pb 一致年龄 $(209 \pm 2) \mathrm{Ma}$, 仍低于 $\mathrm{Sm}-\mathrm{Nd}$ 法的榴辉岩矿物等时 线年龄 $((221 \pm 5) \mathrm{Ma})$. 他们认为这是分析误差所致. 看来, 今后需要的是更为精细的同位素 定年工作. 对大别山超高压变质岩的 P-T t 轨迹研究在这方面提供了一个成功的模式. 李曙 光和肖益林等对安徽太湖县石马地区同一露头的岩石进行了详细的岩石学和年代学综合研 究, 归纳出了超高压变质岩的 P-T t $t$ 轨迹.

值得提及的是, 更为精细的年代学测定工作已经开始在大别山一苏 (北)一鲁 (胶东) 超高 压高质岩带进行. Enami 等 $\left.{ }^{[2]}\right]$ 尝试用电子探针对胶东的榴辉岩及围岩进行了化学 Th-U-Pb 等 时线法 (CHIME 法) 年代学研究. 他们揭示出铅石、针石、独居石等矿物颗粒都具有明显的环 带构造, 各环带 (宽度仅有百分之几毫米) 年龄值竟可相差 $100 \mathrm{Ma}$ 左右. 使用离子探针对榴 辉岩中锆石环带年龄的研究正在顺利进行 (S. Maruyama, 个人通讯, 1993).

\section{4 超高压变质岩的形成与折返机制}

关于超高压变质岩的原岩是一个极值得探讨的问题. 但由于对化学元素 (包括高场强元 素和稀土元素)在超高压条件下的迁移规律不明, 因而使得普通的岩石化学手段受到限制. 如何选择有效的岩石化学和同位素地质学方法与手段进行研究将是今后的工作重点之一. 张 旗和韩宗珠等已分别进行了探索性尝试. 目前的研究表明, 至少一部分超高压变质岩是由陆 壳物质被带至地幔深处变质而成的.

关于超高压变质岩的折返机制一直是国际上的讨论热点, 已提出的折返机制包括浮力 说、内角回流说、后造山拉张说、垫托製张裂说、俯冲带顶举剥蚀说等等. 与之形成对照的 是, 对大别山一苏 (北)一鲁 (胶东) 超高压变质岩带而言, 这方面的讨论尚不多. 这一方面是 由于这一地区的研究刚刚开始, 资料积累不够; 另一方面是由于参与研究的中外学者多侧重 岩石学、矿物学和同位素年代学工作, 对构造地质学缺乏足够的研究. 孙竞雄等对苏北榴辉岩 的宏观变形特征作了初步归纳, 并指出属于榴辉岩退变质变形序列. 索书田等对大别山高压 变质带的变形研究主要限于蓝片岩带.虽然这些研究都没能与岩石的 $P-T$ 轨迹相联系, 但毕竟 是迈出了第一步.

王清晨等 ${ }^{330}$ 把目前已有的折返模式与苏 (北)一鲁 (胶东) 榴辉岩产状作了对比, 提出了榴 辉岩的两阶段折返过程, 认为第一阶段折返以剪切回流为主, 第二阶段折返则以区域性隆起 剥蚀为主. 所谓剪切回流, 实际上是内角回流说的一个翻板. Okay 等 ${ }^{220}$ 则提出大别山超高压变质 岩的折返与陆内逆冲有关. 关于折返机制的进一步讨论将依赖于对大别山一苏 (北)一鲁 (胶东) 超高压变质岩 $P$ (压力) $-T$ (温度) $-t$ (时间)- $D$ (变形) 轨迹的详细研究. 应该指出的. 是, 关于超高压变质岩的折返机制目前在国际上也无定论. 超高压变质岩之所以受到重视, 就是因为它的形成与折返过程向传统的地球动力学观提出了挑战. 可以预言, 这一具有地球 
动力学意义的重要问题仍将是今后一个时期的讨论焦点.

我国大别山一苏(北)一鲁 (胶东) 超高压变质岩带的研究已取得了可喜的成果, 这与中外 科学家的密切合作与努力是分不开的. 客观地讲, 就超高压变质作用的研究而言, 目前我国 科学家在同位素年代学方面、岩石学和矿物学方面基本可以达到国际水平, 而在实验岩石学 和实验矿物学方面则仍为空白, 在变质地质学方面也有一定差距. 好在超高压变质岩的研究 方兴末艾, 相信随着由我国科学家领导的国际岩石圈计划第 III-6任务组“碰撞造山带的超高 压变质作用和地球动力学”研究工作的开展, 我国的超高压变质研究将会取得更大的突破.

致谢 谨向文中提及或未提及的大别山一苏(北)一鲁(胶东) 地区进行超高压变质岩 研究的所有中外研究者表示感谢.

\section{参考文裁}

[1] Chopin, C., Contri. Mineral. Petrol., 1984, 86: 107- 118.

[2] Smith, D. C., Nature, 1989, 310.641- 644.

[3] Xu, Z., These de Docto. at Univ. Sci. Tech Languedoc, Montpelier, 1987.

[4] Wang, X., Liou, J. G., Mao, H. K., Geology, 1989, 17: 1085- 1088.

[5] Okay, A. I., Xu S., Sengor, A. M. C., Eur. J. Mineral., 1989, 1:595- 598.

[6] Xu Shutong, Okay, A. I., Ji, S. et al., Science, 1992, 256: 80- 82.

[7] Zhang R., Hirajima, T., Banno, S. et al., The 15th Intern. Mineral. As Abstracts, 1990, 2:923-924.

[8] Hirajima, T., Ishiwatari, A., Cong, B. et al., Mineral. Magazine, 1990, 54:579-584.

[9] 王晓燕、崔文元, 刘树忠等,岩石学报, 1993, 9: 181-185.

[10] 张儒瑗、刘忠光、王小民等,岩石学报, 1993, 9: 186-191.

[11] Okay, A. I., Sengor, A. M. C., Satir, M., Tectonics, 1993, 12: 1320-1334.

[12] Wang, X., Jing, Y., Liou, J. G. et al., Lithos, 1990, 25:119- 131.

[13] Wang, X., Liou, J. G., Geology, 1991, 19:933-936.

[14] 徐树桐、江来利、刘炲詶等, 地质学报, 1992, 66: 1-4.

[15] 刘若新、马宝林、张兆忠等,地震地质, 1989, 11: 47- 54 .

[16 董树文、孙先如、张勇等,科学通报, 1993, 38: 542- 545 .

[17] Wang, Q., Liu, X., Maruyama, S., GSA Abstracts with Programs, 1993, 25: 5.

[18] Cong, B., Zhai, M., Carswell, D. A. et al., Eur. J. Mineral. 1994 (in press).

[19] Wang, X., Liou, J. G., Maruyama, S., J. Geology, 1992, 100. 231-250.

[20] Okay, A. 1., Sengor, A. M. C., Geology, 1992, 20. 411-414.

[21] Wang, Q., Ishiwatari, A., Zhao, Z. et al., Eur. J. Mineral., 1993, 5: 141- 152.

[22] 刘雅琴、张树业、乔兰勇.地质论评, 1991, 37: 348- 355 .

[23] 畀棋 诚、刘若新、马宝林,岩石学报, 1992, 8: 90-95.

[24] Zhang, R., Liou, J. G., Cong, B., J. Metamorphic Geol., 1994, 12:169- 186.

[25] Yang, J., Godard, G., Kienast, J. et-al., J. Geology, 1993, 101:541- 554.

[26] Okay, A. I., Contrib. Mineral. Petrol., 1994, 116: 145- 155.

[27] Li, S., Wang, S., Chen, Y., Chem. Geol., 1994, 112:343- 350.

[28] Ames, L., Tilton, G. R., Zhou, G., Geology, 1993, 21:339-342.

[29] Enami, M., Suzuki, K., Zhai, M. et al., The Island Arc, 1993, 2:104-113.

[30] 王清展、张霞瑗、从柏林等, 岩石学报, 1992, 8: 153- 160. 